\title{
Conjugate boundary value problems with functional boundary conditions at resonance
}

Weihua Jiang ${ }^{1 *}\left(\mathbb{D}\right.$, Jing Qiu ${ }^{2}$ and Bingzhi Sun ${ }^{1}$

"Correspondence:

jianghua64@163.com

${ }^{1}$ College of Sciences, Hebei

University of Science and

Technology, Shijiazhuang, P.R. China

Full list of author information is

available at the end of the article

\begin{abstract}
By constructing a suitable projection scheme and using the coincidence degree theory of Mawhin, we study the existence of solutions for conjugate boundary value problems with functional boundary conditions at resonance with $\operatorname{dim} \operatorname{Ker} L=1$. Examples are given to illustrate our main results.
\end{abstract}

MSC: 34B10; 34B15

Keywords: Functional boundary conditions; Mawhin's continuation theorem; Fredholm operator; Resonance

\section{Introduction}

In the past years, the conjugate boundary value problems at nonresonance have been studied by many authors [1-13]. The conjugate boundary value problems with specific conditions at resonance have been also investigated (see [14-16] and references therein). For example, in [14], the authors studied the following conjugate problem with boundary conditions:

$$
\begin{aligned}
& (-1)^{n-k} \varphi^{(n)}(x)=f\left(x, \varphi(x), \varphi^{\prime}(x), \ldots, \varphi^{(n-1)}(x)\right), \quad x \in[0,1] \\
& \varphi^{(i)}(0)=\varphi^{(j)}(1)=0, \quad 1 \leq i \leq k-1,0 \leq j \leq n-k-1, \\
& \varphi(0)=\int_{0}^{1} \varphi(x) d A(x) .
\end{aligned}
$$

Du and Ge [15] investigated the existence of solutions for the $(n-1,1)$ conjugate boundary value problems at resonance

$$
\begin{aligned}
& x^{(n)}(t)=f\left(x, x(t), x^{\prime}(t), \ldots, x^{(n-1)}(t)\right)+e(t), \quad \text { a.e. } t \in[0,1], \\
& x(0)=\sum_{i=1}^{m-2} \alpha_{i} x\left(\xi_{i}\right), \quad x^{\prime}(0)=x^{\prime \prime}(0)=\cdots=x^{(n-2)}(0)=0, \quad x(1)=x(\eta) .
\end{aligned}
$$

\section{Springer}

(c) The Author(s) 2019. This article is distributed under the terms of the Creative Commons Attribution 4.0 International License (http://creativecommons.org/licenses/by/4.0/), which permits unrestricted use, distribution, and reproduction in any medium, provided you give appropriate credit to the original author(s) and the source, provide a link to the Creative Commons license, and indicate if changes were made. 
Using Mawhin's continuation theorem [17], Zhao and Liang [18] studied the existence of solutions for the second-order nonlinear boundary value problem

$$
\left\{\begin{array}{l}
x^{\prime \prime}(t)=f\left(t, x(t), x^{\prime}(t)\right), \quad 0<t<1 \\
\Gamma_{1}(x)=0, \quad \Gamma_{2}(x)=0
\end{array}\right.
$$

where $\Gamma_{1}(x)$ and $\Gamma_{2}(x)$ are linear bounded operators. Their results generalize a number of recent works such as multipoint and integral boundary value problems.

Motivated by the literature cited, we study the following conjugate boundary value problems with functional boundary conditions at resonance and $\operatorname{dim} \operatorname{Ker} L=1$ :

$$
\left\{\begin{array}{l}
(-1)^{n-k} \varphi^{(n)}(x)=f\left(x, \varphi(x), \varphi^{\prime}(x), \ldots, \varphi^{(n-1)}(x)\right), \quad x \in[0,1] \\
\varphi^{(i)}(0)=\varphi^{(j)}(1)=0, \quad 0 \leq i \leq k-1,1 \leq j \leq n-k-1, \\
\Gamma(\varphi(x))=0
\end{array}\right.
$$

where $1 \leq k \leq n-1, n \geq 2, \Gamma: C^{n-1}[0,1] \rightarrow \mathbb{R}$ is a linear bounded functional with resonance condition $\Gamma(\Phi(x))=0$, where

$$
\Phi(x)=\frac{(n-1) !}{(k-1) !(n-k-1) !} \int_{0}^{x} t^{k-1}(1-t)^{n-k-1} d t .
$$

This paper is a generalization of two-, three-, and multipoint integral boundary value problems.

The framework of this paper is as follows. In Sect. 2, we give some notations and facts of the coincidence degree theory. In Sect. 3, we investigate problem (1.1). In Sect. 4, we give examples illustrating our main results.

\section{Preliminaries}

We give some theoretical foundations.

Definition 2.1 Let $X$ and $Y$ be real Banach spaces. A linear operator $L: \operatorname{dom} L \subset X \rightarrow Y$ is said to be a Fredholm operator of index zero if

(i) $\operatorname{Im} L$ is a closed subset of $Y$, and

(ii) $\operatorname{dim} \operatorname{Ker} L=\operatorname{codim} \operatorname{Im} L<+\infty$.

Let $L$ be a Fredholm operator of index zero. Let $P: X \rightarrow X$ and $Q: Y \rightarrow Y$ be continuous projectors such that $\operatorname{Im} P=\operatorname{Ker} L, \operatorname{Ker} Q=\operatorname{Im} L, X=\operatorname{Ker} L \oplus \operatorname{Ker} P$, and $Y=\operatorname{Im} L \oplus \operatorname{Im} Q$. It follows that $\left.L\right|_{\operatorname{dom} L \cap \operatorname{Ker} P}: \operatorname{dom} L \cap \operatorname{Ker} P \rightarrow \operatorname{Im} L$ is reversible. We denote the inverse of the mapping $\left.L\right|_{\operatorname{dom} L \cap \operatorname{Ker} P}$ by $K_{P}$. Let $\Omega$ be an open bounded subset of $X$ such that $\operatorname{dom} L \cap$ $\Omega \neq \emptyset$. The mapping $N: X \rightarrow Y$ is called $L$-compact on $\bar{\Omega}$ if $Q N(\bar{\Omega})$ is bounded and $K_{P}(I-$ Q) $N: \bar{\Omega} \rightarrow X$ is compact.

Theorem 2.2 (see [17] Mawhin continuation theorem) Let $L: \operatorname{dom} L \subset X \rightarrow Y$ be a Fredholm operator of index zero, and let $N: X \rightarrow Y$ be L-compact on $\bar{\Omega}$. Assume that the following conditions are satisfied:

(i) $L x \neq \lambda N x$ for every $(x, \lambda) \in[(\operatorname{dom} L \backslash \operatorname{Ker} L) \cap \partial \Omega] \times(0,1)$; 
(ii) $N x \notin \operatorname{Im} L$ for every $x \in \operatorname{Ker} L \cap \partial \Omega$;

(iii) $\operatorname{deg}\left(\left.Q N\right|_{\operatorname{Ker} L}, \Omega \cap \operatorname{Ker} L, 0\right) \neq 0$, where $Q: Y \rightarrow Y$ is a continuous projection such that $\operatorname{Im} L=\operatorname{Ker} Q$.

Then the equation $L x=N x$ has at least one solution in $\operatorname{dom} L \cap \bar{\Omega}$.

Let $X=C^{n-1}[0,1]$ with norm $\|x\|=\max \left\{\|x\|_{\infty},\left\|x^{\prime}\right\|_{\infty}, \ldots,\left\|x^{(n-1)}\right\|_{\infty}\right\}$, where $\|x\|_{\infty}=$ $\max _{t \in[0,1]}|x(t)|$, and let $Y=L^{1}[0,1]$ with norm $\|u\|_{1}=\int_{0}^{1}|u(t)| d t$.

\section{Solvability of problem (1.1)}

We define the operator $L$ by

$$
L \varphi(x)=(-1)^{n-k} \varphi^{(n)}(x)
$$

with

$$
\begin{aligned}
\operatorname{dom} L= & \left\{\varphi \in X: \varphi^{(i)}(0)=\varphi^{(j)}(1)=0,\right. \\
& \left.0 \leq i \leq k-1,1 \leq j \leq n-k-1, \varphi^{(n)} \in Y, \Gamma(\varphi(x))=0\right\} .
\end{aligned}
$$

Define the operator $N: X \rightarrow Y$ as

$$
(N \varphi)(x)=f\left(x, \varphi(x), \varphi^{\prime}(x), \ldots, \varphi^{(n-1)}(x)\right) .
$$

So, problem (1.1) becomes $L \varphi=N \varphi$.

To obtain our main results, we impose the following conditions:

$\left(H_{1}\right) \Gamma\left(\int_{0}^{1} k(x, y) d y\right) \neq 0$, where

$$
k(x, y)= \begin{cases}\frac{1}{(k-1) !(n-k-1) !} \int_{0}^{x(1-y)} t^{k-1}(t+y-x)^{n-k-1} d t, & 0 \leq x \leq y \leq 1 \\ \frac{1}{(k-1) !(n-k-1) !} \int_{0}^{y(1-x)} t^{n-k-1}(t+x-y)^{k-1} d t, & 0 \leq y \leq x \leq 1 .\end{cases}
$$

$\left(H_{2}\right) f:[0,1] \times \mathbb{R}^{n} \rightarrow \mathbb{R}$ satisfies the Carathéodory conditions, that is, $f(\cdot, u)$ is measurable for each fixed $u \in \mathbb{R}^{n}$, and $f(t, \cdot)$ is continuous for a.e. $t \in[0,1]$. In addition, we assume that $\sup \left\{|f(t, x)|: x \in D_{0}\right\}<+\infty$ for any compact set $D_{0} \in \mathbb{R}^{n}$.

$\left(H_{3}\right)$ There exist functions $r(x), q_{i}(x) \in L^{1}[0,1]$ with $\sum_{i=1}^{n}\left\|q_{i}\right\|_{1}<1$ such that

$$
\left|f\left(x, y_{1}, y_{2}, \ldots, y_{n}\right)\right| \leq \sum_{i=1}^{n} q_{i}(x)\left|y_{i}\right|+r(x) \quad \text { for } x \in[0,1] \text { and } y_{i} \in \mathbb{R} \text {. }
$$

$\left(H_{4}\right)$ There exists a constant $M>0$ such that if $\left|\varphi^{(n-1)}(x)\right|>M$ for all $x \in[0,1]$, then

$$
\Gamma\left(\int_{0}^{1} k(x, y) f\left(y, \varphi(y), \varphi^{\prime}(y), \varphi^{\prime \prime}(y), \ldots, \varphi^{(n-1)}(y)\right) d y\right) \neq 0 .
$$

$\left(H_{5}\right)$ There is a constant $a_{0}>0$ such that if $|c|>a_{0}$, then either

$$
c \Gamma\left(\int_{0}^{1} k(x, y) N(c \Phi(y)) d y\right)<0
$$


or

$$
c \Gamma\left(\int_{0}^{1} k(x, y) N(c \Phi(y)) d y\right)>0 .
$$

We now state our main results.

Theorem 3.1 If $\left(H_{1}\right)-\left(H_{5}\right)$ are satisfied, then the functional boundary value problem (1.1) has at least one solution in $X$.

To prove Theorem 3.1, we need the following lemmas.

Lemma 3.2 Assume that $\left(H_{1}\right)$ holds. Then the operator $L: \operatorname{dom} L \subset X \rightarrow Y$ is a Fredholm operator of index zero, and the linear continuous projectors $P: X \rightarrow X$ and $Q: Y \rightarrow Y$ can be defined by

$$
(P \varphi)(x)=\varphi(1) \Phi(x), \quad Q u=\frac{\Gamma\left(\int_{0}^{1} k(x, y) u(y) d y\right)}{\Gamma\left(\int_{0}^{1} k(x, y) d y\right)} .
$$

Furthermore, the linear operator $K_{P}=\left(\left.L\right|_{\operatorname{dom} L \cap \operatorname{Ker} P}\right)^{-1}: \operatorname{Im} L \rightarrow \operatorname{dom} L \cap \operatorname{Ker} P$ is defined as follows:

$$
\left(K_{P} u\right)(x)=\int_{0}^{1} k(x, y) u(y) d y
$$

Proof From $(-1)^{n-k} \varphi^{(n)}(x)=h_{1}(x)$ and $\varphi^{(i)}(0)=0,0 \leq i \leq k-1$, we have

$$
\varphi(x)=\sum_{m=k}^{n-1} \frac{a_{m}}{m !} x^{m}+\frac{(-1)^{n-k}}{(n-1) !} \int_{0}^{x}(x-y)^{n-1} h_{1}(y) d y, \quad 0 \leq x \leq 1 .
$$

Now we will give $\operatorname{Ker} L$ and $\operatorname{Im} L$.

Taking $\varphi(x) \in \operatorname{dom} L$ with $L \varphi=0$, we obtain $\varphi(x)=\sum_{m=k}^{n-1} \frac{a_{m}}{m !} x^{m}$. This, together with $\varphi^{(j)}(1)=0,1 \leq j \leq n-k-1$, implies that [7]

$$
\begin{aligned}
\varphi(x) & =\sum_{j=0}^{n-k-1} \frac{(n-1) !(-1)^{j}(k+j) ! x^{k+j}}{(k-1) ! j !(n-k-j-1) !(k+j)} \varphi(1) \\
& =\frac{(n-1) !}{(n-k-1) !(k-1) !} \sum_{j=0}^{n-k-1} \frac{C_{n-k-1}^{j}(-1)^{j} x^{k+j}}{k+j} \varphi(1) .
\end{aligned}
$$

Since $\sum_{j=0}^{n-k-1} \frac{C_{n-k-1}^{j}(-1)^{j} x^{k+j}}{k+j}=\int_{0}^{x} t^{k-1}(1-t)^{n-k-1} d t$, we get

$$
\varphi(x)=\varphi(1) \frac{(n-1) !}{(k-1) !(n-k-1) !} \int_{0}^{x} t^{k-1}(1-t)^{n-k-1} d t=\varphi(1) \Phi(x) .
$$

It follows from $\Gamma(\Phi(x))=0$ that $\operatorname{Ker} L=\{c \Phi(x), c \in \mathbb{R}\}$. 
To prove that

$$
\operatorname{Im} L=\left\{u \in Y: \Gamma\left(\int_{0}^{1} k(x, y) u(y) d y\right)=0\right\},
$$

take $u \in \operatorname{Im} L$. Then there exists $\varphi \in \operatorname{dom} L$ such that $u=L \varphi \in Y$. From (3.5) and $\varphi^{(j)}(1)=0$, $1 \leq j \leq n-k-1$, we have

$$
\begin{aligned}
\varphi(x)= & \varphi(1) \Phi(x) \\
& +\sum_{j=0}^{n-k-1} \int_{0}^{1} \frac{x^{k+j}}{(k-1) ! j !(n-k-j-1) !} \sum_{i=0}^{j} \frac{C_{j}^{i}(-1)^{j-i} y^{n-k-1-j}(1-y)^{k+i}}{k+i} u(y) d y \\
& +\int_{0}^{x} \frac{(-1)^{n-k}}{(n-1) !}(x-y)^{n-1} u(y) d y .
\end{aligned}
$$

It follows from [7] and (3.5) that

$$
\begin{aligned}
& \sum_{j=0}^{n-k-1} \int_{0}^{1} \frac{x^{k+j}}{(k-1) ! j !(n-k-j-1) !} \sum_{i=0}^{j} \frac{C_{j}^{i}(-1)^{j-i} y^{n-k-1-j}(1-y)^{k+i}}{k+i} u(y) d y \\
& \quad+\int_{0}^{x} \frac{(-1)^{n-k}}{(n-1) !}(x-y)^{n-1} u(y) d y=\int_{0}^{1} k(x, y) u(y) d y .
\end{aligned}
$$

So, we obtain

$$
\varphi(x)=\varphi(1) \Phi(x)+\int_{0}^{1} k(x, y) u(y) d y .
$$

Furthermore, $\varphi \in \operatorname{dom} L$ implies $\Gamma(\varphi(x))=\Gamma\left(\int_{0}^{1} k(x, y) u(y) d y\right)+\varphi(1) \Gamma(\Phi(x))=0$. This, together with $\Gamma(\Phi(x))=0$, means that $\Gamma\left(\int_{0}^{1} k(x, y) u(y) d y\right)=0$. So, we obtain that $\operatorname{Im} L \subset$ $\left\{u: \Gamma\left(\int_{0}^{1} k(x, y) u(y) d y\right)=0\right\}$.

On the other hand, if $u \in Y$ satisfies $\Gamma\left(\int_{0}^{1} k(x, y) u(y) d y\right)=0$, then take

$$
\varphi(x)=\int_{0}^{1} k(x, y) u(y) d y .
$$

Then we conclude that

$$
\begin{aligned}
& L \varphi=(-1)^{n-k} \varphi^{(n)}(x)=u(x), \\
& \varphi^{(i)}(0)=\varphi^{(j)}(1)=0, \quad 0 \leq i \leq k-1,1 \leq j \leq n-k-1,
\end{aligned}
$$

and

$$
\Gamma(\varphi(x))=\Gamma\left(\int_{0}^{1} k(x, y) u(y) d y\right)=0,
$$

that is, $\varphi \in \operatorname{dom} L$, and hence $u \in \operatorname{Im} L$. In conclusion,

$$
\operatorname{Im} L=\left\{u: \Gamma\left(\int_{0}^{1} k(x, y) u(y) d y\right)=0\right\} .
$$


Define the operators $P: X \rightarrow X$ and $Q: Y \rightarrow Y$ by

$$
(P \varphi)(x)=\varphi(1) \Phi(x), \quad Q u=\frac{\Gamma\left(\int_{0}^{1} k(x, y) u(y) d y\right)}{\Gamma\left(\int_{0}^{1} k(x, y) d y\right)} .
$$

Clearly, $P$ and $Q$ are projectors such that $\operatorname{Im} P=\operatorname{Ker} L, \operatorname{Ker} Q=\operatorname{Im} L, X=\operatorname{Ker} L \oplus \operatorname{Ker} P$ and $Y=\operatorname{Im} L \oplus \operatorname{Im} Q$.

Obviously, $\operatorname{Im} L$ is a closed subspace of $Y$, and $\operatorname{dim} \operatorname{Ker} L=\operatorname{codim} \operatorname{Im} L<+\infty$, that is, $L$ is a Fredholm operator of index zero.

We now prove that $K_{P} u \in \operatorname{dom} L \cap \operatorname{Ker} P, u \in \operatorname{Im} L$.

For any $u \in \operatorname{Im} L$, we have $\Gamma\left(\int_{0}^{1} k(x, y) u(y) d y\right)=0$. Since $k(1, y)=0$, we have $K_{P} u(1)=0$, that is, $K_{P} u(x) \in \operatorname{Ker} P$. In addition, it is easy to see that

$$
\left(K_{P} u\right)^{(i)}(0)=0, \quad 0 \leq i \leq k-1 ; \quad\left(K_{P} u\right)^{(j)}(1)=0, \quad 1 \leq j \leq n-k-1 .
$$

Therefore $K_{P} u \in \operatorname{dom} L \cap \operatorname{Ker} P, u \in \operatorname{Im} L$.

Next, we will prove that $K_{P}$ is the inverse of $\left.L\right|_{\operatorname{dom} L \cap \operatorname{Ker} P \text {. }}$

Since $K_{P} u(x)=\int_{0}^{1} k(x, y) u(y) d y$ for $u \in \operatorname{Im} L$, it is clear that

$$
L K_{P} u(x)=(-1)^{n-k}\left(\int_{0}^{1} k(x, y) u(y) d y\right)^{(n)}=u(x)
$$

For each $v \in \operatorname{dom} L \cap \operatorname{Ker} P$, by (3.6) we get

$$
K_{P} L v(x)=\int_{0}^{1} k(x, y) L v(y) d y=v(x)-v(1) \Phi(x)=v(x) .
$$

This implies that $K_{P} L v=v$. So $K_{P}=\left(\left.L\right|_{\operatorname{dom} L \cap \operatorname{Ker} P}\right)^{-1}$. The proof is completed.

Lemma 3.3 $N$ is L-compact on $\bar{\Omega}$ if $\operatorname{dom} L \cap \bar{\Omega} \neq \emptyset$, where $\Omega$ is a bounded open subset of $X$.

Proof Based on $\left(H_{3}\right)$ and the definitions of $Q, K_{P}$, and $k(x, y)$, we can see that $Q N$ is bounded and there exists $g(x) \in L^{1}[0,1]$ such that $|(I-Q) N \varphi| \leq g(x)$, a.e. $x \in[0,1], \varphi \in \bar{\Omega}$. Hence $K_{P}(I-Q) N(\bar{\Omega})$ is bounded. Now we will prove that $K_{P}(I-Q) N(\bar{\Omega})$ is compact.

For $0 \leq x_{1}<x_{2} \leq 1$ and $\varphi \in \bar{\Omega}$, we have

$$
\begin{aligned}
\mid( & \left.K_{P}(I-Q) N \varphi\right)^{(n-1)}\left(x_{1}\right)-\left(K_{P}(I-Q) N \varphi\right)^{(n-1)}\left(x_{2}\right) \mid \\
\quad & =\left|\left(\int_{0}^{1} k(x, y)(I-Q) N \varphi(y) d y\right)^{(n-1)}\left(x_{1}\right)-\left(\int_{0}^{1} k(x, y)(I-Q) N \varphi(y) d y\right)^{(n-1)}\left(x_{2}\right)\right| \\
& =\left|\int_{0}^{x_{1}}(I-Q) N \varphi(y) d y-\int_{0}^{x_{2}}(I-Q) N \varphi(y) d y\right| \\
& =\left|\int_{x_{1}}^{x_{2}}(I-Q) N \varphi(y) d y\right| \leq \int_{x_{1}}^{x_{2}}|g(y)| d y .
\end{aligned}
$$

Considering the absolute continuity of the integral of $g(x)$, we know that $\left\{\left(K_{P}(I-\right.\right.$ Q) $\left.N \varphi)^{(n-1)}: \varphi \in \bar{\Omega}\right\}$ is equicontinuous on $[0,1]$. Since $K_{P}(I-Q) N(\bar{\Omega}) \subset X$ is bounded, 
$\left\{\left(K_{P}(I-Q) N \varphi\right)^{(i)}: \varphi \in \bar{\Omega}, i=0,1, \ldots, n-3, n-2\right\}$ are also equicontinuous on $[0,1]$ by the mean value theorem. It follows from the Lebesgue dominated convergence theorem and conditions $\left(H_{2}\right)$ and $\left(H_{3}\right)$ that $K_{P}(I-Q) N: \bar{\Omega} \rightarrow X$ is a continuous operator. Therefore, by the Ascoli-Arzelà theorem, $K_{P}(I-Q) N: \bar{\Omega} \rightarrow X$ is compact. Thus $N$ is $L$-compact. The proof is completed.

Lemma 3.4 The set

$$
\Omega_{1}=\{\varphi \in \operatorname{dom} L \backslash \operatorname{Ker} L: L \varphi=\lambda N \varphi, \lambda \in[0,1]\}
$$

is bounded if $\left(H_{1}\right)-\left(H_{4}\right)$ are satisfied.

Proof Take $\varphi \in \Omega_{1}$. Then $N \varphi \in \operatorname{Im} L$, and thus we have

$$
\Gamma\left(\int_{0}^{1} k(x, y) f\left(y, \varphi(y), \varphi^{\prime}(y), \ldots, \varphi^{(n-1)}(y)\right) d y\right)=0 .
$$

This, together with $\left(H_{4}\right)$, means that there exists $x_{0} \in[0,1]$ such that $\left|\varphi^{(n-1)}\left(x_{0}\right)\right| \leq M$. It follows from $\varphi^{(i)}(0)=\varphi^{(j)}(1)=0,0 \leq i \leq k-1,1 \leq j \leq n-k-1$, that there exists at least one point $x_{i} \in[0,1]$ such that $\varphi^{(i)}\left(x_{i}\right)=0, i=0,1,2, \ldots, n-2$. Thus we get $\varphi^{(i)}(x)=\int_{x_{i}}^{x} \varphi^{(i+1)}(t) d t$, $i=0,1,2, \ldots, n-2$. So,

$$
\left\|\varphi^{(i)}\right\|_{\infty} \leq\left\|\varphi^{(i+1)}\right\|_{1} \leq\left\|\varphi^{(i+1)}\right\|_{\infty}, \quad i=0,1,2, \ldots, n-2 .
$$

From $\left(H_{3}\right)$, (3.8), and

$$
\begin{aligned}
\varphi^{(n-1)}(x) & =\varphi^{(n-1)}\left(x_{0}\right)+\int_{x_{0}}^{x} \varphi^{(n)}(t) d t \\
& =\varphi^{(n-1)}\left(x_{0}\right)+\lambda \int_{x_{0}}^{x}(-1)^{n-k} f\left(t, \varphi(t), \varphi^{\prime}(t), \ldots, \varphi^{(n-1)}(t)\right) d t
\end{aligned}
$$

we get

$$
\left|\varphi^{(n-1)}(x)\right| \leq M+\sum_{i=1}^{n}\left\|q_{i}\right\|_{1}\left\|\varphi^{(i-1)}\right\|_{\infty}+\|r\|_{1} \leq M+\sum_{i=1}^{n}\left\|q_{i}\right\|_{1}\left\|\varphi^{(n-1)}\right\|_{\infty}+\|r\|_{1} .
$$

Therefore we obtain that

$$
\left\|\varphi^{(n-1)}\right\|_{\infty} \leq \frac{M+\|r\|_{1}}{1-\sum_{i=1}^{n}\left\|q_{i}\right\|_{1}}
$$

So, $\Omega_{1}$ is bounded. The proof of of Lemma 3.4 is completed.

Lemma 3.5 The set

$$
\Omega_{2}=\{\varphi: \varphi \in \operatorname{Ker} L, N \varphi \in \operatorname{Im} L\}
$$

is bounded if $\left(H_{1}\right)-\left(H_{3}\right)$ and $\left(H_{5}\right)$ hold. 
Proof Let $\varphi \in \Omega_{2}$. Then $\varphi(x) \equiv c \Phi(x)$ and $N \varphi \in \operatorname{Im} L$. So, we get

$$
c \Gamma\left(\int_{0}^{1} k(x, y) f\left(y, c \Phi(y), \ldots, c \Phi^{(n-1)}(y)\right) d y\right)=0 .
$$

According to $\left(H_{5}\right)$, we have $|c| \leq a_{0}$, that is, $\Omega_{2}$ is bounded.

Lemma 3.6 The set

$$
\Omega_{3}=\{\varphi \in \operatorname{Ker} L: \lambda J \varphi+\alpha(1-\lambda) Q N \varphi=0, \lambda \in[0,1]\}
$$

is bounded if conditions $\left(H_{1}\right)-\left(H_{3}\right)$ and $\left(H_{5}\right)$ are satisfied, where $J: \operatorname{Ker} L \rightarrow \operatorname{Im} Q$ is the linear isomorphism given by $J(c \Phi(x))=\frac{c}{\Gamma\left(\int_{0}^{1} k(x, y) d y\right)}$, and

$$
\alpha= \begin{cases}-1 & \text { if (3.2) holds } \\ 1 & \text { if (3.3) holds }\end{cases}
$$

Proof Suppose that $\varphi \in \Omega_{3}$. Then $\varphi(x)=c \Phi(x)$ and

$$
\lambda c=-\alpha(1-\lambda) \Gamma\left(\int_{0}^{1} k(x, y) N \varphi(y) d y\right) .
$$

If $\lambda=0$, then by $\left(H_{5}\right)$ we have $|c| \leq a_{0}$. If $\lambda=1$, then $c=0$. If $\lambda \in(0,1)$, then taking $|c|>a_{0}$, we have

$$
\lambda c^{2}=-\alpha(1-\lambda) c \Gamma\left(\int_{0}^{1} k(x, y) N \varphi(y) d y\right)<0,
$$

which contradicts with $\lambda c^{2}>0$. So, Lemma 3.6 holds.

Now we can prove Theorem 3.1.

Proof of Theorem 3.1 Let $\Omega$ be a bounded open subset of $X$ such that $\{0\} \cup \bigcup_{j=1}^{3} \bar{\Omega}_{j} \subset \Omega$. From Lemma 3.3 we know that $N$ is $L$-compact on $\bar{\Omega}$. By Lemmas 3.4 and 3.5 we get:

(i) $L \varphi \neq \lambda N \varphi$ for every $(\varphi, \lambda) \in[(\operatorname{dom} L \backslash \operatorname{Ker} L) \cap \partial \Omega] \times(0,1)$;

(ii) $N \varphi \notin \operatorname{Im} L$ for every $\varphi \in \operatorname{Ker} L \cap \partial \Omega$.

Finally, we will prove (iii) of Theorem 2.2.

Let $H(\varphi, \lambda)=\lambda J \varphi+\alpha(1-\lambda) Q N \varphi$. Noting that $\Omega_{3} \subset \Omega$, we have $H(\varphi, \lambda) \neq 0$ for every $\varphi \in \partial \Omega \cap \operatorname{Ker} L$. Thus by the homotopic property of degree we have

$$
\operatorname{deg}\left(\left.Q N\right|_{\operatorname{Ker} L}, \Omega \cap \operatorname{Ker} L, 0\right)=\operatorname{deg}(\alpha J, \Omega \cap \operatorname{Ker} L, 0) \neq 0 .
$$

By Theorem 2.2 the functional boundary value problem (1.1) has at least one solution in $X$. The proof of Theorem 3.1 is completed. 


\section{Example}

We give two examples to illustrate our main results.

Example 4.1 Consider the boundary value problem

$$
\left\{\begin{array}{l}
\varphi^{(3)}(x)=x-1+\frac{1}{4} \sin \varphi(x)+\frac{1}{4} \sin \varphi^{\prime}(x)+\frac{1}{4} \varphi^{\prime \prime}(x), \quad x \in[0,1] \\
\varphi(0)=0, \quad \varphi^{\prime}(1)=0, \\
\Gamma(\varphi(x))=\varphi^{\prime}(0)-2 \varphi(1)=0 .
\end{array}\right.
$$

Obviously, $n=3, k=1, \Phi(x)=2 x-x^{2}, \Gamma(\Phi(x))=0$, and $\operatorname{Ker} L=\left\{c\left(2 x-x^{2}\right), c \in R\right\}$.

By simple calculation we obtain

$$
\begin{aligned}
\Gamma\left(\int_{0}^{1} k(x, y) d y\right) & =\Gamma\left(\int_{0}^{x} \frac{1}{2} y^{2}(1-x)^{2} d y+\int_{x}^{1}\left[\frac{1}{2} x^{2}(1-y)^{2}+x(y-x)(1-y)\right] d y\right) \\
& =\frac{1}{6} \neq 0, \\
\left|f\left(x, \varphi(x), \varphi^{\prime}(x), \varphi^{\prime \prime}(x)\right)\right| & \leq \frac{1}{4}|\varphi|+\frac{1}{4}\left|\varphi^{\prime}\right|+\frac{1}{4}\left|\varphi^{\prime \prime}\right|+1 .
\end{aligned}
$$

Condition $\left(H_{3}\right)$ is satisfied.

Take $M=7$. If $\varphi^{\prime \prime}(x)>7$, then $f\left(x, \varphi(x), \varphi^{\prime}(x), \varphi^{\prime \prime}(x)\right)>-1-\frac{1}{4}-\frac{1}{4}+\frac{M}{4}>0$, and if $\varphi^{\prime \prime}(x)<-7$, then $f\left(x, \varphi(x), \varphi^{\prime}(x), \varphi^{\prime \prime}(x)\right)<\frac{1}{4}+\frac{1}{4}+\frac{M}{4}<0$. Hence, if $\left|\varphi^{\prime \prime}(x)\right|>M=7$, then

$$
\begin{aligned}
& \Gamma\left(\int_{0}^{1} k(x, y) f\left(y, \varphi(y), \varphi^{\prime}(y), \varphi^{\prime \prime}(y)\right) d y\right) \\
& =\Gamma\left(\int_{0}^{x} \frac{1}{2} y^{2}(1-x)^{2} f\left(y, \varphi(y), \varphi^{\prime}(y), \varphi^{\prime \prime}(y)\right) d y\right. \\
& \left.\quad+\int_{x}^{1}\left[\frac{1}{2} x^{2}(1-y)^{2}+x(y-x)(1-y)\right] f\left(y, \varphi(y), \varphi^{\prime}(y), \varphi^{\prime \prime}(y)\right) d y\right) \\
& =\int_{0}^{1} y(1-y) f\left(y, \varphi(y), \varphi^{\prime}(y), \varphi^{\prime \prime}(y)\right) d y \neq 0 .
\end{aligned}
$$

Thus $\left(H_{4}\right)$ is satisfied.

Finally, take $\varphi \in \operatorname{Ker} L$ and $\varphi(x)=c \Phi(x)=c\left(2 x-x^{2}\right)$. Set $a_{0}=3$. Then we get

$$
c \Gamma\left(\int_{0}^{1} k(x, y) N(c \Phi(y)) d y\right)=c\left(\int_{0}^{1} y(1-y) N(c \Phi(y)) d y\right)<0, \quad|c|>3
$$

since $0 \leq y(1-y) \leq 1, y \in[0,1]$, and

$$
c N(c \Phi(y)) \leq|c|+\frac{1}{4}|c|+\frac{1}{4}|c|-\frac{1}{2} c^{2}<0, \quad|c|>3
$$

Therefore condition $\left(H_{5}\right)$ is satisfied. It follows from Theorem 3.1 that the boundary value problem (4.1) has at least one solution. 
Example 4.2 Consider the other boundary value problem

$$
\left\{\begin{array}{l}
\varphi^{(4)}(x)=x-1+\frac{1}{5} \sin \varphi(x)+\frac{1}{5} \sin \varphi^{\prime}(x)+\frac{1}{5} \sin \varphi^{\prime \prime}(x)+\frac{1}{5} \varphi^{\prime \prime \prime}(x), \quad x \in[0,1] \\
\varphi(0)=\varphi^{\prime}(0)=0, \quad \varphi^{\prime}(1)=0, \\
\Gamma(\varphi(x))=2 \varphi\left(\frac{1}{2}\right)-\varphi(1)=0 .
\end{array}\right.
$$

Obviously, $n=4, k=2, \Phi(x)=3 x^{2}-2 x^{3}, \Gamma(\Phi(x))=0$, and $\operatorname{Ker} L=\left\{c\left(3 x^{2}-2 x^{3}\right), c \in R\right\}$. It is not difficult to verify that $\Gamma\left(\int_{0}^{1} k(x, y) d y\right)=\frac{1}{192} \neq 0$, that is, $\left(H_{1}\right)$ holds.

Obviously, $f$ satisfies $\left|f\left(x, \varphi(x), \varphi^{\prime}(x), \varphi^{\prime \prime}(x), \varphi^{\prime \prime \prime}(x)\right)\right| \leq \frac{1}{5}|\varphi|+\frac{1}{5}\left|\varphi^{\prime}\right|+\frac{1}{5}\left|\varphi^{\prime \prime}\right|+\frac{1}{5}\left|\varphi^{\prime \prime \prime}\right|+1$, where $q_{1}=\frac{1}{5}, q_{2}=\frac{1}{5}, q_{3}=\frac{1}{5}, q_{4}=\frac{1}{5}, r(x)=1$, which verifies condition $\left(H_{3}\right)$.

Take $M=9$. If $\varphi^{\prime \prime \prime}(x)>9$, then $f(x)>-1-\frac{1}{5}-\frac{1}{5}-\frac{1}{5}+\frac{M}{5}>0$, and if $\varphi^{\prime \prime \prime}(x)<-9$, then $f(x)<\frac{3}{5}-\frac{M}{5}<0$.

For convenience, we denote $F(y)=f\left(y, \varphi(y), \varphi^{\prime}(y), \varphi^{\prime \prime}(y), \varphi^{\prime \prime \prime}(y)\right)$. Then

$$
\begin{aligned}
& \Gamma\left(\int_{0}^{1} k(x, y) f\left(y, \varphi(y), \varphi^{\prime}(y), \varphi^{\prime \prime}(y), \varphi^{\prime \prime \prime}(y)\right) d y\right) \\
& \quad=\frac{1}{24}\left(\int_{0}^{\frac{1}{2}}\left(-4 y^{3}+3 y^{2}\right) F(y) d y+\int_{\frac{1}{2}}^{1}\left(4 y^{3}-9 y^{2}+6 y-1\right) F(y) d y\right) \neq 0
\end{aligned}
$$

provided that $\varphi \in \operatorname{dom} L \backslash \operatorname{Ker} L$ satisfies $\left|\varphi^{\prime \prime \prime}(x)\right|>M=9$. Hence $\left(H_{4}\right)$ holds.

Finally, for $\varphi \in \operatorname{Ker} L, \varphi(x)=c \Phi(x)$, we denote $f_{c}(y)=N(c \Phi(y))$. Then, for $|c|>\frac{2}{3}$, we have

$$
\begin{aligned}
& c \Gamma\left(\int_{0}^{1} k(x, y) N(c \Phi(y)) d y\right) \\
& \quad=c \frac{1}{24}\left(\int_{0}^{\frac{1}{2}}\left(-4 y^{3}+3 y^{2}\right) f_{c}(y) d y+\int_{\frac{1}{2}}^{1}\left(4 y^{3}-9 y^{2}+6 y-1\right) f_{c}(y) d y\right)<0,
\end{aligned}
$$

since $0<-4 y^{3}+3 y^{2}<\frac{1}{4}, y \in\left(0, \frac{1}{2}\right), 0<4 y^{3}-9 y^{2}+6 y-1<\frac{1}{4}, y \in\left(\frac{1}{2}, 1\right)$, and

$$
\begin{aligned}
& c N(c \Phi(y)) \\
& \quad=c\left(y-1+\frac{1}{5} \sin \left(c\left(3 y^{2}-2 y^{3}\right)\right)+\frac{1}{5} \sin \left(c 6 y-6 c y^{2}\right)+\frac{1}{5} \sin (6 c-12 c y)+\frac{1}{5}(-12) c\right) \\
& \quad \leq\left(|c|+\frac{3|c|}{5}-\frac{12}{5} c^{2}\right)=\left(\frac{8|c|}{5}-\frac{12}{5} c^{2}\right)<0,|c|>\frac{2}{3} .
\end{aligned}
$$

Then condition $\left(H_{5}\right)$ is satisfied if $a_{0}=\frac{2}{3}$. It follows from Theorem 3.1 that problem (4.2) has at least one solution.

\section{Acknowledgements}

The authors would like to thank the handling editors for the help in the processing of the paper.

\section{Funding}

This work was supported by the Natural Science Foundation of China (11775169), the Natural Science Foundation of Hebei Province (A2018208171), the Graduate Student Innovation Project Fund of Hebei Province (No. XZZSS2017093), and the Foundation of Hebei Education Department (QN2018104). 
Availability of data and materials

Data sharing not applicable to this paper as no datasets were generated or analyzed during the current study.

\section{Competing interests}

The authors declare that they have no competing interests.

\section{Authors' contributions}

All authors read and approved the final manuscript.

\section{Author details}

${ }^{1}$ College of Sciences, Hebei University of Science and Technology, Shijiazhuang, P.R. China. ${ }^{2}$ Cyberspace Institute of Advanced Technology (CIAT), Guangzhou University, Guangzhou, P.R. China.

\section{Publisher's Note}

Springer Nature remains neutral with regard to jurisdictional claims in published maps and institutional affiliations.

\section{Received: 27 July 2018 Accepted: 4 April 2019 Published online: 11 April 2019}

\section{References}

1. Eloe, P.W., Henderson, J.: Positive solutions for $(n-1,1)$ conjugate boundary value problems. Nonlinear Anal. 28 1669-1680 (1997)

2. Eloe, P.W., Henderson, J.: Singular nonlinear $(k, n-k)$ conjugate boundary value problems. J. Differ. Equ. 133, 136-151 (1997)

3. Agarwal, R.P., O'Regan, D.: Multiplicity results for singular conjugate, focal, and (N,P) problems. J. Differ. Equ. 170 , $142-156(2001)$

4. Agarwal, R.P., O'Regan, D.: Positive solutions for $(p, n-p)$ conjugate boundary value problems. J. Differ. Equ. 150 462-473 (1998)

5. Agarwal, R.P., Wong, F.H.: Existence of solutions to $(k, n-k-2)$ boundary value problems. Appl. Math. Comput. 104, 33-50 (1999)

6. Ma, R.: Positive solutions for semipositone $(k, n-k)$ conjugate boundary-value problems. J. Math. Anal. Appl. 252, 220-229 (2000)

7. Kong, L., Wang, J.: The Green's function for $(k, n-k)$ conjugate boundary value problems and its applications. J. Math. Anal. Appl. 255, 404-422 (2001)

8. Jiang, D.: Positive solutions to singular $(k, n-k)$ conjugate boundary-value problems. Acta Math. Sin. 44, 541-548 (2001) (in Chinese)

9. Jiang, W., Zhang, J.: Positive solutions for $(k, n-k)$ conjugate eigenvalue problems in Banach spaces. Nonlinear Anal. 71, 723-729 (2009)

10. Zhang, G.W., Sun, J.X.: Positive solutions of singular $(k, n-k)$ multi-point boundary-value problems. Acta Math. Sin. 49, 391-398 (2006) (in Chinese)

11. Cui, Y., Zou, Y.: Monotone iterative technique for $(k, n-k)$ conjugate boundary value problems. Electron. J. Qual. Theory Differ. Equ. 2015, 69 (2015)

12. Sun, Q., Cui, Y.: Existence results for $(k, n-k)$ conjugate boundary-value problems with integral boundary conditions at resonance with $\operatorname{dim} \operatorname{ker} L=2$. Bound. Value Probl. 2017, 29 (2017)

13. Zhang, X., Zhong, Q.: Uniqueness of solution for higher-order fractional differential equations with conjugate type integral conditions. Fract. Calc. Appl. Anal. 20(6), 1471-1484 (2018)

14. Sun, Q., Cui, Y.: Solvability of $(k, n-k)$ conjugate boundary value problems with integral boundary conditions at resonance. J. Funct. Spaces 2016, Article ID 3454879 (2016)

15. Du, Z., Lin, X., Ge, W.: Some higher-order multi-point boundary-value problem at resonance. J. Comput. Appl. Math. $177,55-65(2005)$

16. Zhang, X., Feng, M., Ge, W.: Existence result of second-order differential equations with integral boundary conditions at resonance. J. Math. Anal. Appl. 353, 311-319 (2009)

17. Mawhin, J.: Topological Degree Methods in Nonlinear Boundary Value Problems. NSF-CBMS Regional Conference Series in Math., vol. 40. Am. Math. Soc., Providence (1979)

18. Zhao, Z., Liang, J.: Existence of solutions to functional boundary value problem of second-order nonlinear differential equation. J. Math. Anal. Appl. 373, 614-634 (2011) 